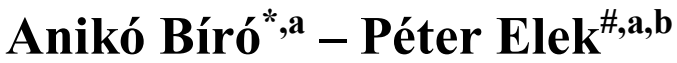 \\ a "Lendület" Health and Population Research Group, \\ Centre for Economic and Regional Studies \\ ${ }^{b}$ Department of Economics, Eötvös Loránd University (ELTE), Budapest, Hungary \\ *Email: biro.aniko@krtk.mta.hu \\ \# Corresponding author, email: peter.elek@tatk.elte.hu
}

\title{
Caesarean delivery and the use of antidepressants
}

This is a pre-copyedited, author-produced version of an article accepted for publication in European Journal of Public Health following peer review.

The version of record (European Journal of Public Health 30(4), 727-733) is available online at: https://doi.org/10.1093/eurpub/ckaa047. 


\begin{abstract}
Background. The high ratio of caesarean sections (C-sections) is a major public health issue in the developed world, but its implications on maternal mental health are not well understood.

Methods. We use individual-level administrative panel data from Hungary between 2010-2016 to analyse the relationship between caesarean delivery and antidepressant consumption, an objective indicator of mental health. We focus on low-risk deliveries of mothers without subsequent birth in three years, and include around 135,000 observations.

Results. After controlling for medical and socio-economic variables, antidepressant use before delivery is associated with an elevated risk of C-section (adjusted $\mathrm{OR}=1.10,95 \% \mathrm{CI} 1.05-1.14$ ) and C-section is associated with a higher probability of antidepressant use within one, two and three years after delivery (e.g. adjusted $\mathrm{OR}=1.21,95 \%$ CI $1.12-1.30$, within three years after delivery, among mothers without pre-delivery antidepressant consumption). Our data restriction ensures that the results are not driven by a mechanical impact of decreasing fertility on the continuation of antidepressant use after a C-section.

Conclusions. The results suggest that $\mathrm{C}$-section is associated with worse mental health over the 1-3 year horizon after birth. This relationship is particularly important if a caesarean delivery is not necessary due to medical reasons, and physicians as well as expectant mothers should be made aware of the potential mental health implications of the mode of delivery.
\end{abstract}

Keywords: antidepressants; caesarean delivery; individual-level administrative data; maternal mental health 


\section{Introduction}

We analyse the relationship between delivery by caesarean section (C-section) among low-risk pregnancies and maternal mental health, where the latter is measured by the consumption of antidepressants. C-section rates are steadily increasing worldwide [1], and Hungary has a much higher C-section rate than e.g. the OECD average ( $37.2 \%$ vs. $28 \%$ in 2015 , see [2]). These high and increasing rates constitute a public health concern because, according to the World Health Organisation, "caesarean sections are effective in saving maternal and infant lives, but only when they are required for medically indicated reasons."[3]

The negative effects of C-sections on infant and maternal health are not well understood. In this paper we focus on maternal mental health, which includes depressive and anxiety disorders. These mental health problems can partly originate from postpartum depression, which has an estimated prevalence of $10-20 \%$ [4-8].

We use an objective indicator of mental health problems, the consumption of antidepressants, which is increasing throughout the developed world. In the OECD, the per capita consumption of antidepressants has more than doubled between 2000 and 2015, and Hungary experienced a similarly huge increase, although per capita consumption is only around half of the OECD average.[2] Thus, in this paper, we analyse the linkage between two phenomena of major health policy interest: caesarean delivery and antidepressant use.

The existing literature on the mental health effects of the mode of delivery is contradictory. A recent systematic literature review [9] summarising mainly observational studies concludes that C-section increases the risk of postpartum depression, while an earlier meta-analysis [10] did not find such a link. Also, a recent paper, using instrumental variable techniques, estimates that caesarean delivery substantially increases the probability of post-traumatic distress and depression.[11] We contribute to this strand of the literature by using an objective indicator of depression (antidepressant use), and by looking at the detailed time pattern of antidepressant use at a long period, up to three years before and three years after delivery. 
Caesarean section and maternal mental health after delivery might be linked through various channels. According to the biopsychosocial model, mental health is shaped by biological, psychological, social and cultural factors.[12] Since these factors are linked to the mode of delivery [13-14], they contribute to an observed relationship between C-section and maternal mental health. First, the decreased levels of oxytocin during a C-section, compared to vaginal delivery, may have direct negative mental health consequences.[15-16] Second, women may experience a deterioration in mood and diminution in self-esteem after caesarean delivery, leading to worse mental health.[17] Third, the psychological and social consequences of the associated maternal and neonatal physical problems [18], such as increased economic vulnerability or limited participation in social life [19], may also play a role. In this study, with our estimates, we also discuss another (but related) channel, lower subsequent fertility after caesarean delivery.

\section{Methods}

\subsection{Institutional setting}

The Hungarian health care system is a comprehensive, compulsory national health insurance scheme, where the majority of outpatient and inpatient care services do not require co-payments, although informal payments ("gratitude money") are common for a wide range of services, including maternity care.[20-21]

Health care provision, including the operation of maternity wards, is based on territorial supply obligation. A pregnant mother should in principle deliver her baby at the hospital to which she belongs based on her place of residence, and - at least outside the capital city - around $75 \%$ of women do so. However, patients are free to choose their physicians, hence women can give birth in another hospital provided that their chosen physician is working there. Hospitals receive more money for a caesarean than for a vaginal delivery within a HDG- (homogeneous disease group) based reimbursement system. The prevalence of home birth is negligible. 
Turning to antidepressants, they are available solely on prescription. Only psychiatrists are allowed to initiate their usage, but general practitioners can also prescribe them for one year based on a written statement from the psychiatrist. On average, patients cover around $30 \%$ of the total price of antidepressants.

\subsection{Data}

We use anonymised administrative data on birth records and on the consumption of antidepressants for the entire population of Hungary for 2010-2016, provided by the Hungarian National Healthcare Service Centre (ÁEEK). The birth records contain the age of the mother, the location (zip code) of her address, the monthly date and zip code of birth, the mode of delivery and the inpatient diagnosis history (ICD codes) of the mother. The pharmaceutical records show data on the consumption of medications in the ATC (Anatomical Therapeutic Chemical) group N06A (antidepressants) that were purchased through pharmacies. The medication records relate only to the ambulatory setting and thus exclude hospital care. We know the exact type and amount of the medication purchased, hence days of therapy (DOT) can be calculated. Based on these data, we create a monthly individual-level panel dataset of birth giving and antidepressant consumption.

We make the following sample restrictions. First, to avoid that earlier or subsequent births confound the results, we consider the first observed deliveries of only those mothers who did not have another delivery within three years afterwards (22\% of all observed first births are excluded). Second, we exclude pregnancies that have a high risk of $\mathrm{C}$-section due to medical reasons: multiple gestation, breech presentation, transverse and oblique lie, face, brow and chin presentation, preterm delivery, obstructed labour due to compound presentation and delayed delivery after rupture of membranes (defined by the ICD codes of the inpatient stay of the delivery). This definition follows the guidelines of the Hungarian Health System Performance Assessment [22] and of the PATH project of the World Health Organisation [23]. With this choice we focus on cases where there is substantial possibility to opt for vaginal delivery and thus to avoid the possible mental health consequences of a C-section. According to our definition, $10.4 \%$ 
of all deliveries are high-risk. C-section rate is $64.2 \%$ within the high-risk, and $34.1 \%$ within the low-risk group. Finally, we restrict the sample to mothers aged 20-40 years.

\subsection{Statistical analysis}

First, we analyse the time pattern of the probability of antidepressant consumption up to three years before and three years after delivery, splitting the sample by the mode of delivery and then also by whether the mother used antidepressants anytime before delivery. We look at quarterly data of antidepressant use, because physicians are allowed to provide prescriptions for up to 3 months' consumption. Also, we examine the monthly patterns of antidepressant use specifically during the pregnancy.

Second, we analyse with a logit model how the prior use of antidepressants (i.e. the binary indicator of antidepressant consumption anytime before delivery) affects the probability of C-section. We control for the age of the mother (with five-year age groups), her earlier health conditions (defined by the following inpatient diagnoses prior to delivery: neoplasm; endocrine, nutritional, mental, circulatory, respiratory and digestive diseases; and diseases of the nervous system), her further gestational risk factors that are not included in the definition of high-risk pregnancies (gestational hypertension, diabetes in pregnancy, malpresentation of the foetus, foetal abnormality and other foetal problems), the type of her settlement, the employment rate at the zip code of her residence, the size (the annual number of births) of the hospital of the delivery and year fixed effects. These variables influence the probability of C-section through health needs or health care supply.

Third, we use logit and ordinary least squares (OLS) models to analyse the association between caesarean delivery and the probability and DOT of subsequent antidepressant use within three years after giving birth, separately on the subsamples split by the pre-delivery use of antidepressants. For mothers without pre-delivery consumption, we also examine the transition rate to antidepressant use, i.e. the probability of starting antidepressants exactly in the first, second or third year after delivery, conditional on no observed usage anytime before. We control for the same maternal and socio-economic variables as in the logit model of caesarean delivery above. 
Fourth, we investigate the heterogeneous impact of C-section on subsequent antidepressant consumption by including interaction terms of caesarean delivery with settlement type. Additionally, to analyse the role of subsequent fertility in the relationship between C-section and antidepressant use, we also estimate our models by including mothers who had another delivery within three years, and, besides, interact the indicator of caesarean delivery with the presence of a subsequent delivery within three years. Finally, we estimate with a logit model how caesarean delivery relates to the probability of having a next birth within three years.

\section{Results}

\subsection{Descriptive analysis}

Table A1 in Appendix shows descriptive statistics of our sample. Antidepressant consumption prior to delivery $(2.6 \%$ of cases $)$ is positively related to the probability of $\mathrm{C}$-section. The prevalence of $\mathrm{C}$-section is $34.9 \%$ among those who did not consume antidepressants before, and 39.0\% among those who did, yielding an unadjusted odds ratio (OR) of 1.22 . Within three years after delivery, $3.6 \%$ of women take some antidepressants, and the ratio is higher among those who delivered with C-section than among those who delivered vaginally $(4.0 \%$ vs. $3.3 \%$, unadjusted $\mathrm{OR}=1.23)$.

Figure 1a displays the quarterly prevalence of antidepressant use as a function of the time measured since delivery, by the mode of delivery. Before pregnancy, the quarterly rate of antidepressant consumption is around $1.0-1.5 \%$, with higher values among those who would later give birth with a C-section. Usage rates fall during pregnancy but remain substantial even in the third trimester (at levels around $0.5 \%$ ). If we zoom in specifically to monthly purchases during pregnancy (Figure 1b), a similar picture emerges, where the share of individuals who consume antidepressants starts to drop around eight

months prior to delivery but roughly levels out during the second half of the pregnancy. Altogether, $1.2 \%$ 
of pregnant women purchase antidepressants at least once during pregnancy, which reflects the controversy around this issue in clinical practice [24].

The ratio of antidepressant users starts to increase right after delivery and reaches the pre-pregnancy level 6-8 quarters after birth giving. Both the level of usage, and the rate of increase are somewhat higher among mothers who had a C-section, and this positive association holds both for mothers without and with previous antidepressant use (Figures 1c and 1d).

\subsection{Baseline estimation results}

The above associations between caesarean delivery and (previous or subsequent) antidepressant consumption persist after controlling for various medical and socio-economic factors. The left panel of Table 1 shows that after taking into account maternal age, other medical conditions, settlement- and hospital-level indicators and year fixed effects, previous antidepressant use still has a substantial positive impact on the probability of caesarean delivery (adjusted OR $=1.10,95 \%$ CI $1.05-1.14$ ). Regarding the effect of the control variables, mothers of higher ages and with medical comorbidities give birth with C-section more often. Also, the C-section rate is higher in better-off settlements (where local unemployment rate is lower) and in larger (typically higher-level) hospitals.

The middle and right panels of Table 1 show the association between caesarean delivery and antidepressant use within three years after delivery, estimated on the two subsamples split by previous antidepressant use, and controlling for the variables as above. C-section implies a very similar increase in the probability of subsequent antidepressant use in the two groups: adjusted OR is 1.21 (95\% CI: 1.12-1.30) for mothers without, and 1.19 (95\% CI: 1.05-1.34) for mothers with previous antidepressant consumption. (Note that the same conclusions are reached from a model estimated on the full sample that contains an interaction term of C-section with the binary indicator of past antidepressant use.) The control parameter estimates in the middle panel show that, for instance, mothers living in better-off settlements are 
more likely to start antidepressants after delivery, perhaps due to the easier access to antidepressants and the better recognition of need there, which is a result of the better availability of psychiatrists.

Table 2 displays that the absolute effect of C-section is larger in the "with" category than in the "without" category: 4 \%points vs. $0.4 \%$ point on the probability of consumption and 37 DOT vs. 1.0 DOT on the amount of consumption (see the second and third columns of the table). Still, as only $2.6 \%$ of mothers used antidepressants previously, slightly more than half of the population-wide DOT effect of C-section comes from the previously non-user group.

Finally, the lower panel of Table 2 shows that caesarean delivery increases not only the stock of antidepressant users, but also the transition probability into antidepressant use as late as three years after delivery. The transition ORs are 1.22, 1.18 and 1.22, respectively, in the first, second and third year after giving birth, and do not differ statistically significantly from each other at the $5 \%$ level.

\subsection{Heterogeneity analysis}

The first panel of Table 3 shows that the positive relationship between caesarean delivery and subsequent antidepressant consumption holds for the residents of all types of settlements, who have very different geographical access to C-section and hence face very different supply constraints. (The parameters are not statistically significantly different across settlement types, $\mathrm{p}$-value $=0.442$ ).

To avoid the potential confounding effect of subsequent deliveries, our results so far were based on the sample of women who did not have another delivery within three years. The lower panel of Table 3 displays the results on the full sample (including mothers with subsequent delivery), and also separately on the two subsamples split according to the birth of another child within three years (examined by an interaction term). The positive association between C-section and subsequent antidepressant consumption is driven by mothers who do not have another delivery within three years (the estimates are slightly larger on the restricted than on the full sample), while the association is not significantly different from zero among mothers who give birth to another child. Meanwhile, in line with the literature (e.g. [25]), our data 
show that after controlling for the usual variables, caesarean delivery decreases the probability of giving birth within three years (logit $\mathrm{OR}=0.781$ with S.E. $=0.010, p<0.01$, on the full sample, not shown in the table).

A subsequent pregnancy after a C-section may mitigate the risk of antidepressant use through two possible channels: a "mechanical" avoidance of antidepressant prescription during pregnancy or a beneficial mental health effect of pregnancy and birth. We cannot dinstinguish these two channels with the data at hand. Overall, our results suggest that if C-section delays the arrival of the next child, then it may lead to an even higher probability of antidepressant use through this channel. However, this does not necessarily reflect worse mental health if subsequent fertility decreases antidepressant use only because antidepressant prescription is not advised during pregnancy.

\section{Discussion}

We analysed the relationship between $\mathrm{C}$-section and antidepressant consumption using administrative data from Hungary. First, we showed that pre-delivery antidepressant use is associated with a higher probability of C-section, controlling for a rich set of demographic, socio-economic and health factors. This is in line with the literature documenting that mental health problems are associated with fear of childbirth [26], with physical health problems [27] and with the probability of elective C-sections [28].

Second, we showed that caesarean delivery is associated with a higher likelihood and higher amounts of antidepressant use over the 1-, 2- and 3-year horizons after delivery, irrespectively of prior antidepressant use or type of settlement. Finally, we provided evidence that the negative relationship between $\mathrm{C}$-section and subsequent fertility further strengthens the association between caesarean delivery and antidepressant use.

To our knowledge, our study is the first to estimate the relationship between caesarean delivery and antidepressant consumption on the basis of a nationwide administrative register and a sufficiently long follow-up period. Compared to two related population-based register studies ([29-30], both on Sweden), 
our outcome measure (antidepressant consumption), our independent variable (all C-sections) as well as the modelling of dynamic effects and transitions are novel.

In the analysis we used a rich set of explanatory variables to control for the determinants of C-section that may be correlated with antidepressant consumption. The stability of the estimated parameters across settlement types suggests that most of these factors have been adequately controlled for - e.g. the relationship is positive even in villages, where maternal request of C-section and quality-based choice of maternity units is less widespread than elsewhere in the country. However, some confounding factors may still remain, and the sign of the bias is not trivial. Unobserved mental health problems might imply an upward bias in our estimates because worse health is associated with a higher probability of C-section. At the same time, if women with better (unobserved) socio-economic conditions within a settlement are more likely to choose C-section and also have easier access to antidepressants - as suggested by our settlement-level control parameters - then this would imply a downward bias. Also, while we restrict the sample to first observed births in our data, we cannot control for unobserved deliveries of the mothers outside our time window (i.e. before 2010), and hence for a possible cumulative effect of previous C-sections.

To eliminate the potential impact of unobserved factors, following [31-32, 11], we also applied instrumental variables regressions, i.e. used potentially exogenous variables that affect the probability of C-section but are otherwise independent of mental health, such as the day of birth (weekday vs. weekend), the relative distance of the mother from hospitals with high vs. low C-section rates, or the presentation of the foetus. The instrumental variables estimates do not contradict the regression estimates presented in this paper, but have too large standard errors to lead to meaningful conclusions, thus we do not include them here.

Some further limitations should be mentioned. Antidepressant use is moderately prevalent in Hungary, compared to other developed countries, and general practitioners cannot prescribe antidepressants without the advise of a psychiatrist. Therefore, our results have limited external validity to countries with more widespread antidepressant use. Easier access to antidepressants would probably make the association 
between caesarean delivery and subsequent antidepressant use even stronger. Relatedly, because of the moderate prevalence of antidepressant use, the true negative effect of $\mathrm{C}$-section on maternal mental health in Hungary might in fact be stronger than suggested by our results.

Also, due to data limitations, we can only speculate about the role of the different channels behind the estimation results. We could not check how the health of the child mediates the relationship between the mode of delivery and antidepressant use. It also remains for future research whether the association differs between elective and non-elective C-sections.

Overall, our results suggest a negative mental health effect of C-section after birth. This relationship is particularly important if a caesarean delivery is not necessary due to medical reasons, and physicians as well as expectant mothers should be made aware of the potential mental health implications.

Funding: The authors were supported by the Momentum ("Lendület") research programme of the Hungarian Academy of Sciences (grant number: LP2018-2/2018). Péter Elek was supported by the János Bolyai Research Scholarship of the Hungarian Academy of Sciences and by the ÚNKP-19-4 New National Excellence Programme of the Hungarian Ministry for Innovation and Technology.

Conflict of interest: none.

Research ethics: The research was approved by the Hungarian Medical Research Council.

Acknowledgment: We thank the Hungarian National Healthcare Service Centre (ÁEEK) for providing the anonymised administrative data within the framework of a research agreement with the Centre for Economic and Regional Studies (CERS). The zip code specific employment rate comes from an individual-level administrative dataset on earnings, processed by the Institute of Economics of CERS. We thank Gábor Kertesi for his help in obtaining the data and for useful comments, Beáta Berkovics and Róbert Károlyi for excellent research assistantship, and two anonymous referees, Norbert Kiss, Péter Mihalicza, Dániel Prinz, Ágnes Szabó-Morvai, Balázs Váradi, seminar participants at the University of Aberdeen and the 4th conference of the Austrian Health Economics Association (ATHEA) for useful comments. 


\section{Key points:}

- We use individual-level administrative panel data from Hungary, covering around 135,000 deliveries, to analyse the relationship between caesarean delivery and antidepressant consumption.

- Antidepressant use before delivery is associated with an elevated risk of $\mathrm{C}$-section (adjusted $\mathrm{OR}=$ $1.10,95 \%$ CI $1.05-1.14)$

- Also, C-section is associated with a higher probability of antidepressant use after delivery (e.g. adjusted $\mathrm{OR}=1.21,95 \%$ CI $1.12-1.30$, within three years after delivery, among mothers without pre-delivery antidepressant consumption).

- Lower subsequent fertility may be a consequence of caesarean delivery, implying higher likelihood of subsequent antidepressant consumption.

- Physicians and expectant mothers should be made aware of the mental health implications of the mode of delivery. 


\section{References}

[1] Betrán AP, Ye J, Moller A-B, Zhang J, Gülmezoglu AM, Torloni MR. The increasing trend in caesarean section rates: global, regional and national estimates: 1990-2014. PloS ONE 2016; 11(2):e0148343. URL https://doi.org/10.1371/journal.pone.0148343.

[2] OECD. Health at a Glance 2017: OECD Indicators. Paris: OECD Publishing, 2017. URL https://doi.org/10.1787/health $\backslash$ s $\backslash$ do6(g)lance-2017-en.

[3] WHO. WHO statement on caesarean section rates, 2015.

https://www.who.int/reproductivehealth/publications/maternal/s\do6(p)erinatal/s\do6(h)ealth/cs-statement/ en/ Accessed 2018-10-09.

[4] O'hara MW, Swain AM. Rates and risk of postpartum depression: a meta-analysis. Int Rev Psychiatr 1996; 8(1):37-54. URL https://doi.org/10.3109/09540269609037816.

[5] Beck CT. Predictors of postpartum depression: an update. Nurs Res 2001; 50(5):275-285. URL http://doi.org/10.1097/00006199-200109000-00004.

[6] Payne JL. Antidepressant use in the postpartum period: practical considerations. Am J Psychiat 2007; 164(9):1329-1332. URL https://doi.org/10.1176/appi.ajp.2007.07030390.

[7] Kozinszky Z, Dudas RB, Csatordai S et al. Social dynamics of postpartum depression: a population-based screening in South-Eastern Hungary. Soc Psych Psych Epid 2001; 46(5):413-423. URL https://doi.org/10.1007/s00127-010-0206-2.

[8] Nagy E, Molnar P, Pal A, Orvos H. Prevalence rates and socioeconomic characteristics of post-partum depression in Hungary. Psychiat Res 2011; 185(1-2):113-120. URL

https://doi.org/10.1016/j.psychres.2010.05.005. 
[9] Xu H, Ding Y, Ma Y, Xin X, Zhang D. Cesarean section and risk of postpartum depression: A meta-analysis. J Psychosom Res 2017; 97:118-126. URL https://doi.org/10.1016/j.jpsychores.2017.04.016.

[10] Carter FA, Frampton CM, Mulder RT. Cesarean section and postpartum depression: a review of the evidence examining the link. Psychosom Med 2006; 68(2):321-330. URL https://doi.org/10.1097/01.psy.0000204787.83768.0c.

[11] Tonei V. Mother's mental health after childbirth: Does the delivery method matter? J Health Econ 2019; 63:182-196. URL https://doi.org/10.1016/j.jhealeco.2018.11.006.

[12] Ayers S, Ford E.. Psychosocial context of illness and well-being in women's health. In Edozien LC, O’Brien PMS, editors. Biopsychosocial Factors in Obstetrics and Gynaecology. Cambridge: Cambridge University Press, 2017:8-14. URL https://doi.org/10.1017/9781316341261.003.

[13] Buultjens M, Murphy G, Robinson P, Milgrom J. The perinatal period: A literature review from the biopsychosocial perspective. Clinical Nursing Studies 2013; 1(3):19-31. https://doi.org/10.5430/cns.v1n3p19.

[14] Witt WP, Wisk LE, Cheng ER et al. Determinants of cesarean delivery in the US: a lifecourse approach. Matern Child Health J 2015; 19(1):84-93. URL https://doi.org/10.1007/s10995-014-1498-8. [15] Kim S, Soeken TA, Cromer SJ, Martinez SR, Hardy LR, Strathearn L. Oxytocin and postpartum depression: Delivering on what's known and what's not. Brain Res 2014; 1580:219-232. URL https://doi.org/10.1016/j.brainres.2013.11.009.

[16] Chen H-H, Lai JC-Y, Hwang S-J, Huang N, Chou Y-J, Chien L-Y. Understanding the relationship between cesarean birth and stress, anxiety, and depression after childbirth: A nationwide cohort study. Birth 2017; 44(4):369-376. URL https://doi.org/10.1111/birt.12295. 
[17] Fisher J, Astbury J, Smith A. Adverse psychological impact of operative obstetric interventions: a prospective longitudinal study. Aust NZ J Psychiat 1997; 31(5):728-738. URL https://doi.org/10.3109/00048679709062687.

[18] Costa-Ramón AM, Rodríguez-González A, Serra-Burriel M, Campillo-Artero C. It's about time: Cesarean sections and neonatal health. J Health Econ 2018; 59:46-59. URL https://doi.org/10.1016/j.jhealeco.2018.03.004.

[19] Hutton G. The effect of maternal-newborn ill-health on households: economic vulnerability and social implications. Geneva: World Health Organisation, 2006. URL

https://apps.who.int/iris/handle/10665/43515

[20] Orosz É, Burns A. The healthcare system in Hungary. OECD Economics Department Working Paper 241, Paris: OECD Publishing; 2000. URL https://doi.org/10.1787/088362842087.

[21] Baji P, Rubashkin N, Szebik I, Stoll K, Vedam S. Informal cash payments for birth in Hungary: Are women paying to secure a known provider, respect, or quality of care? Soc Sci Med 2017; 189:86-95. https://doi.org/10.1016/j.socscimed.2017.07.015.

[22] Hungarian National Healthcare Service Centre (ÁEEK). Health system performance assessment. 2018. https://mertek.aeek.hu/ Accessed 2018-10-09.

[23] National Center for Quality Assessment in Health Care and World Health Organisation. PATH Indicators Descriptive Sheets '09/10. http://www.pathqualityproject.eu/upLoad/file/path_20092010_indicators_descriptive_sheets.pdf Accessed 2019-11-08.

[24] Molenaar NM, Kamperman AM, Boyce P, Bergink V. Guidelines on treatment of perinatal depression with antidepressants: An international review. Aust NZ J Psychiat 2018; 52:320-327. URL https://doi.org/10.1177/0004867418762057. 
[25] Gurol-Urganci I, Bou-Antoun S, Lim C et al. Impact of caesarean section on subsequent fertility: a systematic review and meta-analysis. Hum Reprod 2013; 28(7):1943-1952. URL https://doi.org/10.1093/humrep/det130.

[26] Rouhe H, Salmela-Aro K, Gissler M, Halmesmäki E, Saisto T. Mental health problems common in women with fear of childbirth. BJOG-Int J Obstet Gy 2011; 118(9):1104-1111. URL https://doi.org/10.1111/j.1471-0528.2011.02967.x.

[27] Osborn DP. Topics in review: The poor physical health of people with mental illness. Western J Med 2001; 175(5):329-332. URL https://doi.org/10.1136/ewjm.175.5.329.

[28] Olieman RM, Siemonsma F, Bartens MA, Garthus-Niegel S, Scheele F, Honig A. The effect of an elective cesarean section on maternal request on peripartum anxiety and depression in women with childbirth fear: a systematic review. BMC Pregnancy Childb 2017; 17(1):195. URL https://doi.org/10.1186/s12884-017-1371-z.

[29] Sydsjö G, Möller L, Lilliecreutz C, Bladh M, Andolf E, Josefsson A. Psychiatric illness in women requesting caesarean section. BJOG-Int J Obstet Gy 2015; 122(3):351-358. URL https://doi.org/10.1111/1471-0528.12714.

[30] Möller L, Josefsson A, Bladh M, Lilliecreutz C, Andolf A, Sydsjö G. Mental health after first childbirth in women requesting a caesarean section; a retrospective register-based study. BMC Pregnancy Childb 2017; 17(1):326. URL https://doi.org/10.1186/s12884-017-1514-2.

[31] Halla M, Mayr H, Pruckner GJ, García-Gómez P. Cutting fertility? The effect of cesarean deliveries on subsequent fertility and maternal labor supply. IZA Discussion Paper No. 9905, IZA Institute of Labour Economics; 2016. URL https://www.iza.org/publications/dp/9905.

[32] Card D, Fenizia A, Silver D. The health effects of cesarean delivery for low-risk first births. NBER Working Paper 24493, National Bureau of Economic Research; 2018. URL https://doi.org/10.3386/w24493. 
Table 1: Logit models describing the relationship between caesarean delivery and previous / subsequent antidepressant use (models of subsequent antidepressant use are estimated on samples split according to the binary indicator of previous antidepressant use)

$\begin{array}{cc}\text { probability of } & \text { probability of antidepressant use } \\ \text { Dependent variable } & \text { within } 3 \text { years after birth }\end{array}$
prev. antidep use: prev. antidep use:

no yes

logit odds ratio logit odds ratio logit odds ratio

\begin{tabular}{|c|c|c|c|c|c|c|}
\hline & Est. & S.E. & Est. & S.E. & Est. & S.E. \\
\hline antidep. use before delivery & $1.095 * * *$ & {$[0.021]$} & & & & \\
\hline caesarean delivery & & & $1.207 * * *$ & {$[0.046]$} & $1.189 * * *$ & {$[0.075]$} \\
\hline \multicolumn{7}{|l|}{ age $($ baseline $=20-24$ years $)$} \\
\hline - 25-29 years & $1.218 * * *$ & {$[0.014]$} & 0.930 & {$[0.056]$} & $1.270^{*}$ & {$[0.156]$} \\
\hline - 30-34 years & $1.373 * * *$ & {$[0.016]$} & $0.839 * * *$ & [0.049] & $1.627 * * *$ & [0.189] \\
\hline - $35-40$ years & $1.432 * * *$ & {$[0.018]$} & $0.900 *$ & {$[0.056]$} & $1.751 * * *$ & {$[0.207]$} \\
\hline other gest. risk factors & $2.211 * * *$ & {$[0.018]$} & 1.034 & {$[0.045]$} & 1.020 & {$[0.072]$} \\
\hline \multicolumn{7}{|l|}{ pre-delivery inpatient diagnoses } \\
\hline - neoplasm & $1.303 * * *$ & {$[0.032]$} & 1.014 & {$[0.137]$} & 0.899 & [0.133] \\
\hline - endocrine, nutritional & $1.353 * * *$ & {$[0.034]$} & $1.252^{*}$ & {$[0.153]$} & 0.928 & [0.164] \\
\hline - mental & 0.952 & {$[0.033]$} & $4.137 * * *$ & {$[0.577]$} & $1.657 * * *$ & {$[0.172]$} \\
\hline - nervous system & $1.326^{* * *}$ & {$[0.053]$} & $1.552 * *$ & {$[0.290]$} & 1.144 & {$[0.220]$} \\
\hline - circulatory & $1.312 * * *$ & {$[0.037]$} & $1.681 * * *$ & [0.208] & 0.796 & {$[0.145]$} \\
\hline - respiratory & $1.068 * * *$ & {$[0.026]$} & $1.429 * * *$ & {$[0.177]$} & 0.971 & [0.168] \\
\hline - digestive & $1.203 * * *$ & {$[0.024]$} & $1.324 * * *$ & [0.138] & 1.120 & [0.169] \\
\hline \multicolumn{7}{|l|}{ living area (baseline $=$ Budapest) } \\
\hline - other town & $1.021 * *$ & {$[0.010]$} & 1.004 & {$[0.053]$} & $0.780 * * *$ & {$[0.066]$} \\
\hline - village & 0.983 & {$[0.011]$} & 0.973 & {$[0.057]$} & $0.759 * * *$ & {$[0.072]$} \\
\hline zip code spec. emp. rate & $2.504 * * *$ & {$[0.143]$} & $2.873 * * *$ & [0.867] & 0.945 & {$[0.476]$} \\
\hline annual nr. of births in hosp $(1,000)$ & $1.068 * * *$ & {$[0.003]$} & $0.974 * *$ & [0.013] & $0.963^{*}$ & {$[0.020]$} \\
\hline \multicolumn{7}{|c|}{ year $($ baseline $=$ first year $(2010$ or 2011$))$} \\
\hline 2011 & $1.035 * * *$ & {$[0.012]$} & & & $0.389 * * *$ & [0.048] \\
\hline 2012 & $1.108 * * *$ & {$[0.014]$} & $0.825 * * *$ & {$[0.034]$} & $0.264 * * *$ & {$[0.032]$} \\
\hline
\end{tabular}


N. of obs.

Period 2010-2016

Standard errors in brackets, ${ }^{* * *} \mathrm{p}<0.01,{ }^{* *} \mathrm{p}<0.05,{ }^{*} \mathrm{p}<0.1$. Sample: age $20-40$, low risk, first observed birth, and in the models of antidepressant use: no subsequent birth within 3 years. Other gestational risk factors: gestational hypertension, diabetes in pregnancy, malpresentation of the foetus, foetal abnormality and other foetal problems. 
Table 2: Relationship between caesarean delivery and subsequent antidepressant use on different time spans and different subsamples

\begin{tabular}{|c|c|c|c|c|}
\hline & \multicolumn{3}{|c|}{ Effect of caesarean delivery on } & \multirow{3}{*}{$\begin{array}{l}\text { N. of } \\
\text { obs. }\end{array}$} \\
\hline & \multicolumn{2}{|c|}{$\begin{array}{l}\text { probability of } \\
\text { antidep. use }\end{array}$} & \multirow{2}{*}{$\begin{array}{c}\text { DOT of } \\
\text { antidep. use } \\
\text { OLS }\end{array}$} & \\
\hline & logit OR & OLS & & \\
\hline \multicolumn{5}{|c|}{ Mothers without pre-delivery antidepressant use } \\
\hline \multirow[t]{2}{*}{$0-36$ months after birth } & $1.207 * * *$ & $0.00449 * * *$ & $1.03 * * *$ & \multirow{2}{*}{131,159} \\
\hline & {$[0.046]$} & {$[0.00092]$} & {$[0.30]$} & \\
\hline \multicolumn{5}{|c|}{ Mothers with pre-delivery antidepressant use } \\
\hline \multirow[t]{2}{*}{$0-36$ months after birth } & $1.189 * * *$ & $0.0390 * * *$ & $36.73 * * *$ & \multirow{2}{*}{4,923} \\
\hline & [0.075] & {$[0.0142]$} & {$[12.74]$} & \\
\hline \multicolumn{5}{|c|}{ Transition to antidepressant use (for mothers without antidepressant use) } \\
\hline \multirow[t]{2}{*}{$0-12$ months after birth } & $1.218^{* * *}$ & $0.00153 * * *$ & & \multirow{2}{*}{131,159} \\
\hline & {$[0.081]$} & {$[0.00052]$} & & \\
\hline \multirow[t]{2}{*}{ 13-24 months after birth } & $1.181 * * *$ & $0.00142 * *$ & & \multirow[t]{2}{*}{130,170} \\
\hline & {$[0.075]$} & {$[0.00055]$} & & \\
\hline \multirow[t]{2}{*}{ 25-36 months after birth } & $1.217 * * *$ & $0.00162 * * *$ & & \multirow{2}{*}{129,080} \\
\hline & {$[0.080]$} & {$[0.00055]$} & & \\
\hline
\end{tabular}

Standard errors in brackets (OLS: heteroscedasticity-robust), ${ }^{* * *} \mathrm{p}<0.01,{ }^{* *} \mathrm{p}<0.05,{ }^{*} \mathrm{p}<0.1$. Odds ratios (ORs) from logit models as well as effects from ordinary least squares (OLS) models are shown. Controls: 5-year age groups, other gest. risk factors, pre-delivery inpatient diagnoses, type of settlement, zip code specific employment rate, annual nr. of births in hospital, year dummies. Sample: age 20-40, low risk, first observed birth, no subsequent birth within 3 years. Period: 2011-2013 for non-users, 2010-2013 for users. 
Table 3: Heterogeneity of the relationship between C-section and subsequent antidepressant use

probability of antidepressant use

within 3 years after birth

logit OR p-value

Est. S.E. for equality of interactions

Model: interaction with type of settlement 0.442

caesarean $\mathrm{x}$ capital city

$1.302 * * *$

[0.116]

caesarean $\mathrm{x}$ other town

$1.157^{* * *}$

[0.060]

caesarean $\mathrm{x}$ village

$1.247^{* * *}$

[0.086]

Model: full sample (including mothers with subsequent delivery within three years)

caesarean

$1.193^{* * *}$

[0.043]

Model: interaction with birth within 3 years on the full sample

0.003

caesarean $\mathrm{x}$ no birth within 3 years

$1.204 * * *$

caesarean $\mathrm{x}$ any birth within 3 years

0.832

[0.098]

Number of observations: 131,159 in the first model, 169,188 in the last two models. Standard errors in brackets, ${ }^{* * *} \mathrm{p}<0.01,{ }^{* *} \mathrm{p}<0.05, * \mathrm{p}<0.1$. Controls in each model: 5 -year age groups, other gest. risk factors, pre-delivery inpatient diagnoses, type of settlement, zip code specific employment rate, annual nr. of births in hospital, year dummies. Sample: without pre-delivery antidepressant use, age 20-40, low risk, first observed birth, no subsequent birth within 3 years after delivery. Period: 2011-2013 
Figure 1: Rate of antidepressant use by the time since delivery and mode of birth (sample: age 20-40, low risk, first observed birth, no subsequent birth within 3 years)
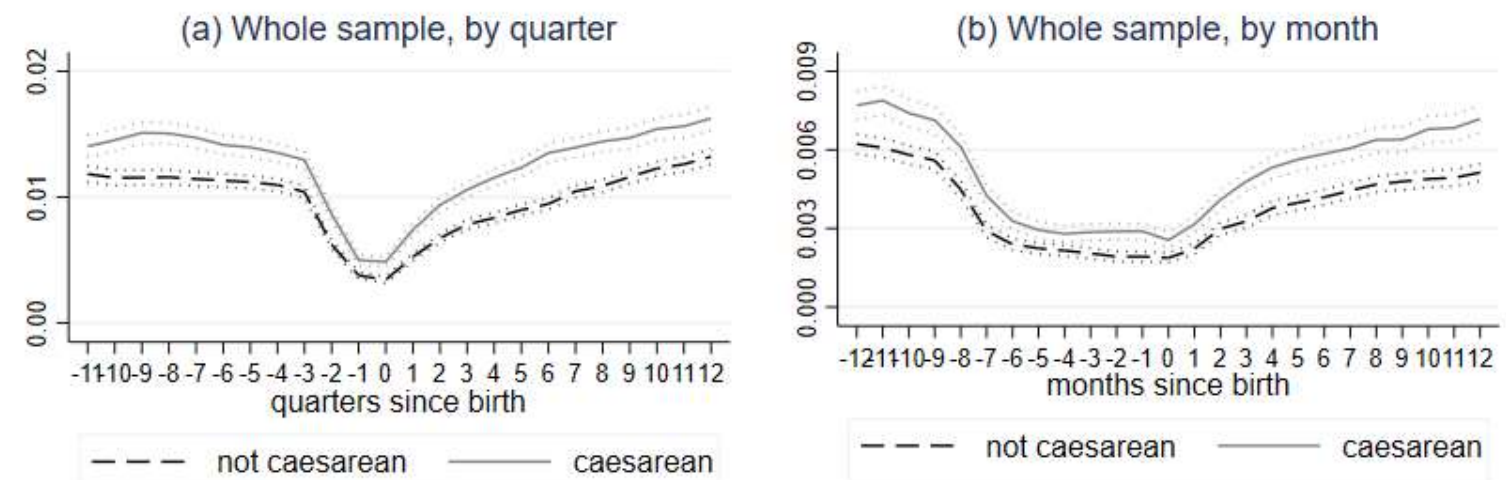

(c) No observed use before delivery, by quarter

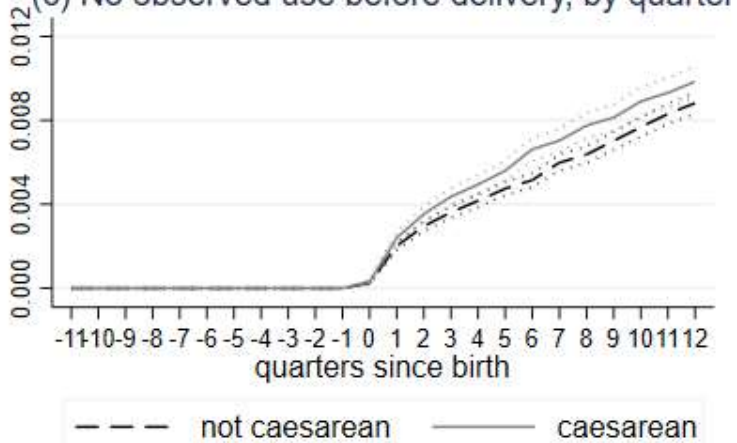

(d) With observed use before delivery, by quarter

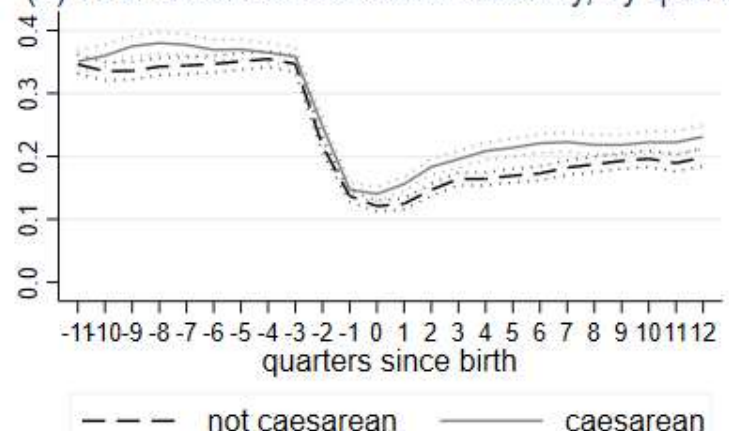

